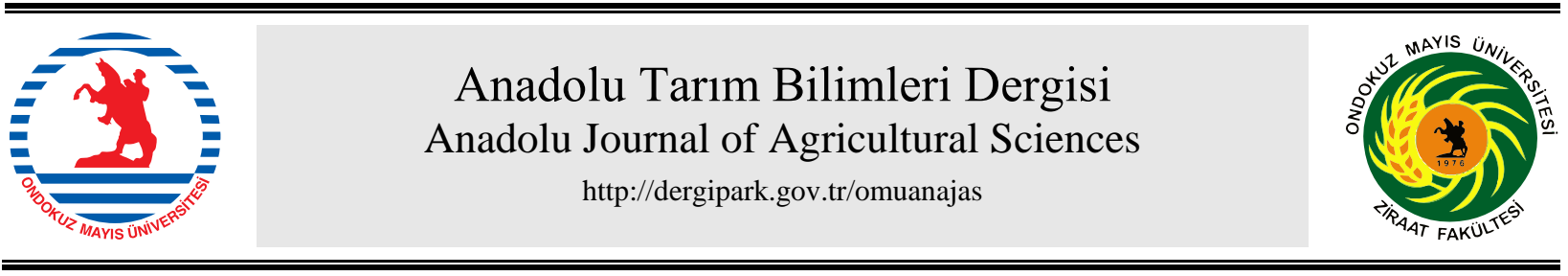

\title{
Araştırma/Research
}

Anadolu Tarım Bilim. Derg./Anadolu J Agr Sci, 34 (2019) ISSN: 1308-8750 (Print) 1308-8769 (Online) doi:10.7161/omuanajas.440508

\section{Hasat zamanının Katran yoncasının (Bituminaria bituminosa) besin madde kompozisyonu, in vitro gaz ve metan üretimi üzerindeki etkisi}

\author{
Kevser Durmaz Adem Kamalak* \\ Kahramanmaraş Sütçü İmam Üniversitesi, Ziraat Fakültesi, Zootekni Bölümü, Kahramanmaraş, Türkiye \\ * Sorumlu yazar/corresponding author: akamalak@ksu.edu.tr
}

Geliş/Received 04/07/2018～Kabul/Accepted 18/11/2018

\begin{abstract}
OZET
Bu çalışmanın amacı, katran yoncası otunun besin madde kompozisyonu, gaz üretimi, metan üretimi, organik madde sindirim derecesi (OMSD) ve metabolik enerjisi (ME) üzerine hasat zamanının etkisini belirlemektir. Üç farklı dönemde hasat edilen katran yoncasının kompozisyonu belirlendikten sonra in vitro gaz üretim testine tabi tutulmuştur. Katran yoncasının yirmi dört saatlik gaz üretim değerleri kullanılarak ME ve OMSD belirlenmiştir. Katran yoncası otunun kuru madde (KM), nötral deterjan lif (NDF) ve asit deterjan lif (ADF) içerikleri hasat zamanının ilerlemesiyle birlikte artmasına rağmen ham kül (HK), ham protein (HP) içerikleri ve nispi yem değerinde (NYD) önemli azalmalar meydana gelmiştir. Katran yoncası otunun KM, NDF, ADF ve kondense tanin (KT) içerikleri ve NYD'leri farklı hasat devrelerinde $\% 20.1$ ile $33.9, \% 45.0$ ile $66.1, \% 25.8$ ile $42.5,0.96$ ile 1.25 ve 78.3 ile 141.85 arasında değişmiştir. Hasat zamanının ilerlemesiyle birlikte katran yoncası otunun in vitro gaz ve metan üretimi (ml), ME ve OMSD değerleri sirasiyla 41.8 ile $50.4 \mathrm{ml}, 6.95$ ile $7.70 \mathrm{ml}, 9.28$ ile $11.0 \mathrm{MJ} \mathrm{kg}^{-1}$ KM ve \% 63.6 ile 76.5 arasında değişmiştir. Hasat zamanının ilerlemesiyle birlikte kaçınılmaz kayıplar olmasına rağmen katran yoncasının tohum bağlama döneminde bile ruminant hayvanların besin maddeleri ihtiyacınının karşılanması amacıyla rasyonlarda kullanılabileceği ileri sürülebilmekle birlikte bu konuda daha detaylı çalışmalara ihtiyaç bulunmaktadır.
\end{abstract}

Effect of harvest stage on the chemical composition, in vitro gas and methane production of Bituminaria bituminosa

\section{ABSTRACT}

The aim of the current experiment was to determine the effect of harvest stage on the chemical composition, in vitro gas and methane production, organic matter digestibility and metabolisable energy of Bituminaria bituminosa. After determination of chemical composition, Bituminaria bituminosa hay was subjected to the test of in vitro gas production. The metabolisable energy and organic matter digestibility of Bituminaria bituminosa hay were determined using the gas production at $24 \mathrm{~h}$ incubation. Harvest stage had a significant effect on the chemical composition of Bituminaria bituminosa hay. Dry matter, neutral detergent fiber and acid detergent fiber contents of Bituminaria bituminosa hay increased while crude ash, crude protein contents and relative feed value decreased with advancing maturity. Dry matter, neutral detergent fiber, acid detergent fiber, condensed tannin and relative feed value of Bituminaria bituminosa hay ranged from 20.1 to $33.9 \%, 45.0$ to $66.1 \%, 25.8$ to $42.5 \%, 0.96$ to $1.25 \%$ and 78.3 to 141.85 respectively. On the other hand, crude ash and crude protein of Bituminaria bituminosa hay ranged from 7.96 to 9.51 and 14.2 to $23.6 \%$ respectively. In vitro gas production, methane production (as $\mathrm{ml}$ ), metabolizable energy and organic matter digestibility of Bituminaria bituminosa hay ranged from 41.8 to $50.4 \mathrm{ml}, 6.95$ to $7.70 \mathrm{ml}, 9.28$ to $11.0 \mathrm{MJ} \mathrm{kg}^{-1} \mathrm{DM}$ and 63.6 to $76.5 \%$ respectively and decreased with increasing maturity whereas the percentage of methane increased with increasing maturity. Although the inevitable loss in nutritive value of Bituminaria bituminosa plant with advancing maturity, even at the seeding stage, Bituminaria bituminosa plant could provide hay of acceptable quality for ruminant animals to meet their requirements. In addition, low level of condensed tannin in Bituminaria bituminosa offers an opportunity to decrease the risk of bloat for grazing ruminant animals. But this needs verification with further testing.
Anahtar Sözcükler:

Besin madde kompozisyonu Besleme değeri Gaz üretimi Hasat zamanı Katran yoncas Metan üretimi

Keywords:

Nutrient composition Nutritive value Gas production Harvesting stage Methane production

(C) OMU ANAJAS 2019 


\section{Giriş}

Bir baklagil mera bitkisi olan Bituminaria bituminosa otu koyun ve keçiler tarafından yaz aylarında tüketilmekte ve halk arasında katran yoncası olarak bilinmektedir. Türkiye'de merada bulunan birçok otun kimyasal kompozisyonu, besleme değeri hasat zamanına bağlı olarak belirlenmesine rağmen katran yoncasının kompozisyonu ve besleme değeri üzerinde yeterli sayıda çalışma bulunmamaktadır (Kamalak ve ark., 2010; Kamalak ve ark., 2011; Kaplan ve ark., 2014a, b). Hayvanların otlatma planlamasının doğru bir şekilde yapılması için merada bulunan bitkilerin besleme değerlerinin büyüme evrelerine göre belirlenmesi gereklidir (Valente ve ark., 2000). Bu kapsamda son zamanlarda daha önce üzerinde fazla bir çalışma olmayan yem bitkilerinin kompozisyonunu, metabolik enerji ve organik madde sindirim derecesini belirlemek için bazı araştırmalar yürütülmüştür (Kamalak ve ark., 2010; Kamalak ve ark., 2011; Canbolat, 2012; Güven, 2012; Kaya ve Kamalak, 2012). Yemlerin rumendeki fermentasyonu sırasında önemli miktarda açı̆̆a çıkan enterik metan önemli düzeyde enerji kaybı (\%2-12) ve çevre kirliliğine neden olmaktadır (Johnson ve Johnson, 1995). Metan gazının küresel 1sınma etkinliği $\mathrm{CO}_{2}$ 'e göre 23 kat daha fazladır. Hem çevre kirliliğine neden olan hem de küresel 1sınmaya neden olan enterik metan üretimi in vitro gaz üretim tekniği kullanılarak belirlenebilmektedir (Goel ve ark., 2008; Kaplan ve ark., 2014a, b; Ulger ve ark., 2017). Bu çalışmanın amacı, katran yoncası otunun besin madde kompozisyonu, gaz üretimi, metan üretimi, organik madde sindirim derecesi ve metabolik enerjisi üzerine hasat zamanının etkisini belirlemektir.

\section{Materyal ve Yöntem}

Katran yoncası bitkisi çiçeklenme öncesi (15.04.2013), çiçeklenme (07.05.2013) ve tohum bağlama (11.06.2013) dönemi olmak üzere merada oluşturulmuş parsellerden $(5 \mathrm{X} 2 \mathrm{~m})$ üç tekerrürlü olarak hasat edilmiştir. Toplanan katran yoncası bitkisi laboratuara getirilerek gölgede kurutulmuştur. Kurutulmuş katran yoncası $1 \mathrm{~mm}$ elekten geçecek şekilde ögütülerek plastik torbalarda kimyasal analizler ve gaz üretim testi için buzdolabında saklanmıştır.

Katran yoncasının kuru madde içeriği $105{ }^{0} \mathrm{C}$ kurutularak ve ham kül içeriği ise $525{ }^{\circ} \mathrm{C}$ 'de yakılarak belirlenmiştir (AOAC, 1990). Katran yoncasının ham protein içeriği Kjeldahl metoduna göre (AOAC, 1990), nötral deterjan lif ve asit deterjan lif içeriği ise Van Soest ve ark. (1991) tarafından geliştirilen metoda göre yapılmıştır. Katran yoncasının kondense tanin içeriği Butanol-HCl metoduna göre yapılmıştır (Makkar ve ark., 1995). Hasat zamanının ilerlemesiyle birlikte HP, NDF ve NDF içeriklerindeki günlük azalma, çiçeklenme öncesi ile tohum bağlama dönemindeki HP, NDF ve
NDF içerikleri arasındaki farkın iki dönem arasındaki gün farkına bölünmesiyle bulunmuştur.

Katran yoncasının NYD aşağıda belirtilen formüller kullanılarak belirlenmiştir (Rohweder ve ark., 1978).

$\% \mathrm{KMSD}=88.9-(0.779 * \% \mathrm{ADF})$

$\mathrm{KMT}=120 / \% \mathrm{NDF}$

$\mathrm{NYD}=(\% \mathrm{KMSD} * \% \mathrm{KMT}) / 1.29$

KMSD (\%): Kuru madde sindirim derecesi

$\mathrm{ADF}=$ Asit deterjan lif $(\%)$

KMT = Kuru madde tüketimi (Vücut ağırlığının \%'si olarak),

NYD $=$ Nispi yem değeri

Katran yoncasının in vitro gaz ve metan ölçümlerinin yapılabilmesi için Kahramanmaraş Sütçü İmam Üniversitesi, Ziraat Fakültesi Yerel Etik kutulundan onay alınmıştır (Etik Kurul Rapor No: 2016/6-3). Çalışmada gaz ve metan üretimi in vitro gaz üretim tekniği ile belirlenmiştir (Menke ve ark., 1979). Bunun için yaklaşık $200 \mathrm{mg}$ katran yoncası $30 \mathrm{ml}$ tamponlanmış rumen sıvısıyla üç tekerrürlü olarak 24 saat inkübasyona bırakılmıştır. Rumen sıvısı \% 60 yonca kuru otu ve $\% 40$ arpadan oluşan rasyonla beslenen üç adet erkek koyundan elde edilmiştir. Yirmi dört saatlik net gaz üretimi kör ve standart yem (Hohenheim Üniversitesi, Almanya) göz önüne alınarak hesaplanmıştır. Üretilen gazın metan içeriği (\%) metan analiz cihazı (Sensor Europe GmbH, Erkrath, Almanya) kullanılarak belirlenmiştir (Goel ve ark., 2008).

Metan $(\mathrm{mL})=$ Toplam gaz üretimi $(\mathrm{mL}) \mathrm{X} \operatorname{metan}(\%)$

Katran yoncasının metabolik enerji(ME) içeriği ((MJ $\mathrm{kg}^{-1} \mathrm{KM}$ ) ve organik madde sindirim derecesi (OMSD) Menke ve Steingass (1988) önerdiği aşağıdaki eşitlikler kullanılarak hesaplanmıştır.

$\mathrm{ME}\left(\mathrm{MJ} \mathrm{kg}^{-1} \mathrm{DM}\right)=1.68+0.1418 \mathrm{GP}+0.073 \mathrm{CP}+$
$0.217 \mathrm{EE}-0.028 \mathrm{CA}$

OMSD $(\%)=14.88+0.8893 \mathrm{GP}+0.448 \mathrm{CP}+$ $0.651 \mathrm{CA}$

$\mathrm{GP}=24$ saatlik net gaz üretimi $(\mathrm{ml} / 200 \mathrm{mg})$,

$\mathrm{HP}=$ Ham protein $(\%)$

HY: Ham yağ (\%)

HK: Ham kül (\%)

Katran yoncası otunun kimyasal kompozisyonu, gaz üretimi, metan üretimi, organik madde sindirim derecesi ve metabolik enerjisi üzerine hasat zamanının etkisini belirlemek için elde edilen veriler varyans analizine (ANOVA) tabi tutulmuş ve ortalamalar arasındaki farklar Tukey çoklu karşılaştırma testiyle belirlenmiştir. 


\section{Bulgular ve Tartışma}

\subsection{Katran yoncası otunun kimyasal kompozisyonuna hasat zamanının etkisi}

Katran yoncasının kimyasal kompozisyonuna hasat zamanının etkisi Çizelge 1'de verilmiştir. Çizelge 1'de görüldüğü gibi hasat zamanı katran yoncasının kimyasal kompozisyonunu önemli derecede etkilemiş olup, hasat zamanının ilerlemesiyle birlikte elde edilen otun KM, NDF, ADF ve KT içeriği yükselmiş diğer taraftan HP ve NYD önemli derecede azalmıştır. Katran yoncasının KM, NDF, NDF ve KT içerikleri sırasıyla \% 20.1 ile $33.9, \% 45.0$ ile $66.1, \% 25.8$ ile 42.5 , \% 0.96 ile 1.25 arasında değişmiştir. Diğer taraftan katran yoncasının HK, HP ve NYD'leri sirasiyla \% 7.96 ile 9.51 ve \% 14.2 ile 23.6 ve \% 78.3 ile 141.8 arasında değișmiştir. Bu çalışmaya konu olan katran yoncasının HP ve ADF içerikleri Ventura ve ark. (2004) bulgularıyla uyum içerisinde olurken NDF içeriği Ventura ve ark. (2004) bildirdiği değerden yüksek bulunmuştur. Ventura ve ark. (2004) katran yoncasının HP ve ADF içeriklerini sirasıyla $\% 17.3$ ile 20 ve 25.6 ile \% 36.8 olarak NDF içeriğini ise \% 38.0 ile 48.1 olarak bildirmiştir.

$\mathrm{Bu}$ çalışmada, katran yoncasının HP içeriğindeki günlük azalma ( $1.62 \mathrm{~g} \mathrm{~kg}^{-1} \mathrm{KM}$ ) Kamalak ve ark. (2011) ve Kaplan ve ark. (2014a) akboyotu ve çayır düğmesi otları için bildirilen değerlerden (sırasıyla 2.34 ve 2.54 $\mathrm{g} / \mathrm{kg}$ ) daha düşük bulunmuştur. Diğer taraftan bu çalışmada elde edilen katran yoncasının HP içeriğindeki günlük azalma dar yapraklı üçgül otunda gözlenen azalmadan (Kamalak ve Canbolat, 2010; 0,84 g kg-1 KM) daha yüksek bulunmuştur. Görüldüğü gibi farklı bitki türleri arasında HP içeriğinde hasat zamanına bağlı olarak meydana gelen azalma bakımından önemli farklar mevcuttur. $\mathrm{Bu}$ farklılıkların söz konusu bitki türünün yetiştirildiği bölgenin iklimsel farklılıklarından kaynaklandığı bildirilmiştir (Kaplan ve ark., 2014a).

Hasat zamanının ilerlemesiyle birlikte katran yoncasının NDF ve ADF içeriklerinde sırasıyla 3.64 ve $2.88 \mathrm{~g} / \mathrm{kg}$ günlük artış tespit edilmiştir. Katran yoncasının NDF içeriğindeki artış çayır düğmesinde gözlemlenen artıştan yüksek, ADF içeriğinde daha düşük bulunmuştur. Kaplan ve ark. (2014a) çayır düğmesiyle yaptığı çalışmada NDF ve ADF içeriklerindeki artışı sırasıyla 3.32 ve $3.41 \mathrm{~g} \mathrm{~kg}^{-1}$ olarak bulmuştur.

Hasat zamanının ilerlemesiyle birlikte katran yoncasının HP içeriğindeki meydana gelen azalmanın yaprak:sap oranındaki düşüşle ilişkili olduğu düşünülmektedir. Stavarache ve ark. (2015), yoncayla yaptığ yaprak:sap oranının \% 59'dan \% 27'ye düştüğünü bildirmiştir. Yapraklar sapa oranla protein bakımından zengin olmasına rağmen, NDF ve ADF bakımından fakirdir. Dolayısıyla hasat zamanının ilerlemesiyle birlikte bitkilerin HP içeriğinin NDF ve ADF lehine azalması kaçınılmazdır.

Yemlerde bulunan yüksek düzeyde yer alan KT'ler mikro-organizmaların faaliyetlerini doğrudan etkileyebileceği gibi mikroorganizmaların salgıladığ1 enzimlerle kompleks oluşturarak dolaylı etki yapabilirler (Singleton, 1981; Lohan ve ark., 1983; Barry ve Duncan, 1984; Makkar ve ark., 1989). Diğer taraftan düşük seviyedeki (\% 2-3) KT rumende proteinlerle kompleks oluşturarak proteinlerin aşırı parçalanmasını önlemek suretiyle rumende yıkıma dirençli protein miktarını artırabilir (Barry ve Blaney, 1987). Rasyonda KT içeriğinin \% 5 üzerinde olması durumunda ruminant hayvanlarda yem tüketiminin önemli derecede azaldığ1 bildirilmiştir (Frutos ve ark., 2004). Bu çalışmaya konu olan katran yoncasının KT içeriği \% 5 'den düşük olduğu için ruminant havyanlar üzerinde zararlı bir etkisinin olacağı ihtimali düşük gözükmektedir.

Çizelge 1. Hasat zamanının katran yoncasının kimyasal kompozisyonu üzerindeki etkisi

\begin{tabular}{|c|c|c|c|c|c|}
\hline \multicolumn{6}{|c|}{ Hasat Zamanı } \\
\hline & $\begin{array}{c}\text { Çiçeklenme } \\
\text { öncesi }\end{array}$ & Çiçeklenme & Tohum bağlama & SHO & $P$ \\
\hline $\mathrm{KM}^{\mathrm{x}}$ & $20.1^{\mathrm{c}}$ & $24.6^{\mathrm{b}}$ & $33.9^{\mathrm{a}}$ & 0.896 & $<0.001$ \\
\hline $\mathrm{HK}^{\mathrm{y}}$ & $9.51^{\mathrm{a}}$ & $8.13^{\mathrm{b}}$ & $7.96^{\mathrm{b}}$ & 0.209 & 0.001 \\
\hline $\mathrm{HY}^{\mathrm{y}}$ & $3.53^{\mathrm{b}}$ & $3.07^{\mathrm{c}}$ & $3.90^{\mathrm{a}}$ & 0.071 & $<0.001$ \\
\hline $\mathrm{HP}^{\mathrm{y}}$ & $23.6^{\mathrm{a}}$ & $16.8^{\mathrm{b}}$ & $14.2^{\mathrm{c}}$ & 0.076 & $<0.001$ \\
\hline $\mathrm{NDF}^{\mathrm{y}}$ & $45.0^{c}$ & $55.3^{\mathrm{b}}$ & $66.1^{\mathrm{a}}$ & 1.015 & $<0.001$ \\
\hline $\mathrm{ADF}^{\mathrm{y}}$ & $25.8^{\mathrm{c}}$ & $37.9^{\mathrm{b}}$ & $42.5^{\mathrm{a}}$ & 0.764 & $<0.001$ \\
\hline $\mathrm{KT}^{\mathrm{y}}$ & $0.95^{\mathrm{b}}$ & $1.07^{\mathrm{ab}}$ & $1.25^{\mathrm{a}}$ & 0.062 & 0.007 \\
\hline NYD & $141.8^{\mathrm{a}}$ & $99.8^{\mathrm{b}}$ & $78.3^{\mathrm{c}}$ & 1.623 & $<0.001$ \\
\hline
\end{tabular}

${ }^{a b c}$ Aynı satırda ayn simgeye sahip olan ortalamalar arasinda fark yoktur (P<0.05) SHO: Standard hata ortalamasl; KM: Kuru madde (\%), HK: Ham kül (\%), HY: Ham yağ (\%), HP: Ham protein (\%), NDF: Nötral deterjan lif (\%), ADF: Asit deterjan lif (\%), KT: Kondense tanin (\%). ${ }^{x}$ : 100 gram taze yemdeki miktarl (\%), ${ }^{X}$ : 100 gram kuru maddedeki miktarl (\%) 
3.2. Katran yoncasinın in vitro gaz üretimi, metan üretimi, metabolik enerji ve organik madde sindirim derecesi üzerine hasat zamanının etkisi

Katran yoncasının in vitro gaz üretimi, metan üretimi, ME ve OMSD üzerindeki hasat zamanının etkisi Çizelge 2'de verilmiştir.

Hasat zamanının ilerlemesiyle birlikte gaz üretimi, metan üretimi, ME ve OMSD azalmış olup söz konusu parametrelerdeki değişim sırasıyla 41.8 ile $50.4 \mathrm{ml}, 6.95$ ile $7.70 \mathrm{ml}, 9.28$ ile $11.0 \mathrm{MJ} \mathrm{kg}^{-1} \mathrm{KM}$ and $\% 63.6$ ile 76.5 arasında olmuştur. Bazı araştırmacılar dar yapraklı üçgül otu, akboyotu, çayır düğmesi ve yabani korunga otlarıyla yaptıkları çalışmada hasat zamanının ilerlemesiyle birlikte ME ve OMSD'de benzer düşüşler olduğunu bildirmişlerdir (Kamalak ve Canbolat, 2010; Kamalak ve ark., 2011; Kaplan ve ark., 2014a, b).

Genel olarak gaz ve metan üretimi, ME ve OMSD yemlerde bulunan fermente olabilen madde miktarındaki artışa bağlı olarak yükselir. Daha önce bahsedildiği gibi hasat zamanının ilerlemesiyle birlikte katran yoncasının NDF ve ADF içeriği protein içeriği aleyhine artmıştır. Başka ifadeyle hasat zamanın ilerlemesiyle birlikte fermente olan maddelerin miktarı azalmış buna bağlı olarak katran yoncasının gaz üretimi, metan üretimi, sindirim derecesi ve metabolik enerji içeriği azalmıştır.

Fermantasyon sırasında çıkan gazın metan içeriğine göre yemlerin anti-metanojenik özellik bakımından üç grupta sınıflandırabileceği bildirilmiştir (Lopez ve ark., 2010). Fermantasyon sırasında çıkan gazın metan içeriğinin \%11 ile 14 arasında olan yemleri düşük antimetanojenik potansiyelli olarak, \% 6 ile 11 arasında orta anti-metanojenik, $\% 0$ ile 6 arasında yüksek antimetanojenik potansiyelli olarak sınıflandırmıştır. Bundan dolayı katran yoncasının her üç dönemde metan içeriği \%14'den yüksek olduğu için anti-metanojenik özelliğinin olmadığı söylenebilir.

Çizelge 2. Hasat zamanının Katran yoncasının in vitro gaz üretimi, metan üretimi, metabolik enerji ve organik madde sindirim derecesi üzerindeki etkisi

\begin{tabular}{|c|c|c|c|c|c|}
\hline \multicolumn{6}{|c|}{ Hasat Zamanı } \\
\hline & $\begin{array}{l}\text { Çiçeklenme } \\
\text { öncesi }\end{array}$ & Çiçeklenme & Tohum bağlama & $\mathrm{SHO}$ & $P$ \\
\hline $\mathrm{Gaz}(\mathrm{ml})$ & $50.4^{\mathrm{a}}$ & $45.9^{\mathrm{b}}$ & $41.8^{c}$ & 0.817 & 0.011 \\
\hline $\mathrm{CH}_{4}(\mathrm{ml})$ & $7.70^{\mathrm{a}}$ & $7.12^{\mathrm{b}}$ & $6.95^{\mathrm{b}}$ & 0.171 & 0.001 \\
\hline $\mathrm{CH}_{4}(\%)$ & $15.2^{\mathrm{b}}$ & $15.4^{b}$ & $16.6^{\mathrm{a}}$ & 0.173 & $<0.001$ \\
\hline $\mathrm{ME}$ & $11.0^{\mathrm{a}}$ & $9.87^{b}$ & $9.28^{c}$ & 0.114 & $<0.001$ \\
\hline OMSD & $76.5^{\mathrm{a}}$ & $68.6^{b}$ & $63.6^{\mathrm{c}}$ & 0.655 & $<0.001$ \\
\hline
\end{tabular}

abc Aynı simgeye sahip ve aynı satırda yer alan ortalamalar arasinda fark yoktur ( $P<0.05)$ SHO: Standard hata ortalamasi; ME: Metabolik enerji (MJ $\left.\mathrm{kg}^{-1} \mathrm{KM}\right)$, OMSD: Organik madde sindirim derecesi (\%)

\section{Sonuç}

Mevcut çalışmada ele alınan katran yoncasının, yem değerinde hasat zamanının ilerlemesiyle birlikte kaçınılmaz kayıplar olmasına rağmen, tohum bağlama döneminde bile ruminant hayvanların besin maddeleri ihtiyacınının karşılanmasında kullanılabileceği söylenebilir. Ayrıca, düşük seviyede KT içeren katran yoncası otunun merada otlayan ruminant hayvanlarda şişme riskini azaltıcı rol oynayabilir.

\section{Teşekkür}

Bu çalışma Kahramanmaraş Sütçü İmam Üniversitesi Bilimsel Araştırma Projeleri Birimi (Proje no: 2016/613 YLS) tarafindan desteklenmiştir.

\section{Kaynaklar}

AOAC., 1990. Official Method of Analysis. Association of Official Analytical Chemists, $15^{\text {th }}$ Edition, Washington, DC. USA.

Barry, T.N., Duncan S.J., 1984. The role of condensed tannins in the nutritional value of Lotus pedunculatus for sheep. I. Voluntary intake. British Journal of Nutrition, 51, 485-491

Barry, T.N., Blaney, B.J., 1987. Secondary compounds of forages. In: Hacker, J.B. and Ternouth, J.H. (eds) Nutrition of Herbivores, pp. 91-120. (Academic Press: Sydney).

Canbolat, O., 2012. Potential nutritive value of field bindweed (Convolvulus arvensis L) hay harvested at three different maturity stages. Journal of the Faculty of Veterinary Medicine, Kafkas University, 18(2): 331-335.

Frutos, P., Hervas, G., Giraldez, F.J., Mantecon, A.R., 2004. Review. Tannins and ruminant nutrition. Spanish Journal of Agricultural Research, 2: 191-202.

Goel, G., Makkar, H.P.S., Becker, K., 2008. Effect of Sesbania sesban and Carduus pycnocephalus leaves and Fenugreek (Trigonella foenum-graecum $\mathrm{L}$ ) seeds and their extract on partitioning of nutrients from roughage-and concentrate-based feeds to methane. Animal Feed Science and Technology, 147(1-3): 7289.

Guven, I., 2012. Effect of species on nutritive value of mulberry leaves. Journal of the Faculty of Veterinary Medicine, Kafkas University, 18(5): 865-869. 
Johnson, K.A. „Johnson, D.E., 1995. Methane emissions from cattle. Journal of Animal Science, 73: 24832492.

Kamalak, A., Canbolat. O., 2010. Determination of nutritive value of wild narrow-leaved clover (Trifolium angustifolium) harvested at three maturity stages using chemical composition and in vitro gas production. Trop. Grassland, 44(2): 128-133.

Kamalak, A., Atalay, A.I., Ozkan, C.O., Kaya, E., Tatliyer, A., 2011. Determination of potential nutritive value of Trigonella kotshi Fenzl hay harvested at three different maturity stages. Journal of the Faculty of Veterinary Medicine, Kafkas University, 17(4): 635-640.

Kaplan, M., Kamalak, A., Kasra., A.A., Guven, I., 2014 a. Effect of maturity stages on potential nutritive value, methane production and condensed tannin content of Sanguisorba minor hay. Journal of the Faculty of Veterinary Medicine, Kafkas University, 20(3): 445449.

Kaplan, M., Kamalak, A., Ozkan, C.O., Atalay. A.I., 2014b. Effect of vegetative stages on the potential nutritive value, methane production and condensed tannin content of Onobrychis caput-galli hay. Journal of the Faculty of Veterinary Medicine, Harran University. 3(1): 1-5.

Kaya, E., Kamalak, A., 2012. Potential nutritive value and condensed tannin contents of acorns from different oak species. Journal of the Faculty of Veterinary Medicine, Kafkas University, 18(6): 1061-1066.

Lohan, O.P., Lall, D., Vaid, J., Negi, S.S., 1983. Utilization of oak tree fodder in cattle ration and fate of oak leaf tannins in the ruminant system. Indian Journal of Animal Science, 53: 1057-1063.

Lopez, S., Makkar, H.P.S., Soliva, C.R., 2010. Screening plants and plant products for methane inhibitors. In: Vercoe PE, Makkar HPS, Schlink A, (Eds): In vitro screening of plant resources for extra nutritional attributes in ruminants: Nuclear and related methodologies. London, New York, pp. 191-231.

Makkar, H.P.S., Singh, B., Negi, S. S., 1989. Relationship of rumen degradability with microbial colonization, cell wall constituents and tannin levels in some tree leaves. Animal Production, 49: 299-303.

Makkar, H.P.S., Blummel, M., Becker, K., 1995. Formation of complexes between polyvinyl pyrrolidones or polyethylene glycols and their implication in gas production and true digestibility in vitro techniques. British Journal of Nutrition, 73: 897913.

Menke, K.H., Raab, L., Salewski, A., Steingass, H., Fritz, D., Schneider, W., 1979. The estimation of digestibility and metabolizable energy content of ruminant feedstuffs from the gas production when they incubated with rumen liquor in vitro. Journal of Agricultural Science (Cambridge), 92: 217-222.

Menke, H.H., Steingass, H., 1988. Estimation of the energetic feed value obtained from chemical analysis and in vitro gas production using rumen fluid. Animal Research and Development, 28: 7-55.

Singleton, V.L., 1981. Naturally occurring food toxicants: Phenolic substances of plant origin common in foods. Advances in Food Research, 27: 149-242.

Stavarache, M., Samuil, C., Popovici, C.I., Tarcau, D., Vint, V., 2015. The productivity and quality of alfalfa (Medicago sativa L.) in Romanian forest stepe. Notulae Botanicae Horti Agrobotanici, 43(1): 179185.

Rohweder, D.A., Barnes, R.F., Jorgensen, N., 1978. Proposed hay grading standards based on laboratory analyses for evaluating quality. Journal of Animal Science, 47: 747-759.

Ulger, I., Kamalak, A., Kurt, O., Kaya, E., Guven, I., 2017. Comparison of the chemical composition and anti-methanogenic potential of Liquidamber orientalis leaves with Laurus nobilis and Eucalyptus globulus using an in vitro gas production technique. Ciencia Investigacion Agraria, 44(1): 75-82.

Van Soest, P.J., Robertson, J.B. Lewis, B.A., 1991. Methods for dietary fiber, neutral detergent fiber, and nonstarch polysaccharides in relation to animal nutrition. Journal of Dairy Science, 74(10): 35833597.

Valente, M.E., Borreani, G., Peiretti, P.G., Tobacco, E., 2000. Codified morphological stage for predicting digestibility of Italian ryegrass during the spring cycle. Agronomy Journal, 92: 967-973.

Ventura, M.R., Castanon, J.I.R., Pieltain, M.C., Flores, M.P., 2004. Nutritive value of forage shrubs: Bituminaria bituminosa, Rumex lunaria, Acacia salicina, Cassia sturtii and Adenocorpus foliosus. Small Ruminant Research, 52: 13-18. 